JPSE

(Journal of Physical Science and Engineering)

\title{
Sintesis Kalium Ferrat sebagai Pendegradasi Senyawa Turunan Benzena
}

\begin{tabular}{l}
\hline Received \\
28 Juni 2019 \\
Revised \\
21 Agustus 2019 \\
Accepted for Publication \\
26 November 2019 \\
Published \\
28 Februari 2020 \\
\hline
\end{tabular}

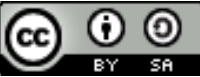

This work is licensed under a Creative Commons AttributionShareAlike 4.0 International License.

\author{
D Majid $^{1 *}$, A R Prabowo ${ }^{2}$, M Al-Kholif ${ }^{1}$, dan Sugito ${ }^{1}$ \\ 1. Teknik Lingkungan, Fakultas Teknik, Universitas PGRI Adi Buana, Surabaya 60234, Indonesia \\ 2. Teknik Mesin, Fakultas Teknik, Universitas Sebelas Maret, Surakarta 57126, Indonesia \\ *E-mail: majid@unipasby.ac.id
}

\begin{abstract}
This research was carried out in order to synthesize potassium ferrate $\left(\mathrm{K}_{2} \mathrm{FeO}_{4}\right)$ and was applied to the degradation of benzene derivative compounds such as chlorobenzene, bromobenzene, and toluene. In this study, potassium ferrate has been successfully generated from four different source of $\mathrm{Fe} ; \mathrm{FeSO}_{4} .9 \mathrm{H}_{2} \mathrm{O}, \mathrm{FeCl}_{2} .9 \mathrm{H}_{2} \mathrm{O}, \mathrm{Fe}\left(\mathrm{NO}_{3}\right)_{2} .9 \mathrm{H}_{2} \mathrm{O}$, and $\mathrm{NaFeO}_{2}$. The potassium ferrate crystal has a black purplish color. The sample was analyzed by UVVis spectrophotometer. We noted that ferrate has wavelength of $510 \mathrm{~nm}$. The potassium ferrate that synthesized from $\mathrm{NaFeO}_{2}$ has highest purity compared to other samples. The result of degradation test, ferrate degradated by toluene has the highest degradation efficiency of $53 \%$ within 10 minutes of reaction time. This showed that potassium ferrate became the promising alternative material for water processing and wastewater of industries. Keywords: potassium ferrate, benzene, degradation.
\end{abstract}

\begin{abstract}
Abstrak
Penelitian ini dilakukan dengan tujuan untuk menyintesis kalium ferrat $\left(\mathrm{K}_{2} \mathrm{FeO}_{4}\right)$ dan diaplikasikan pada degradasi senyawa turunan benzene seperti klorobenzena, bromobenzena, dan toluena. Pada penelitian ini, kalium ferrat telah berhasil disintesis dengan mengunakan empat sumber Fe yang berbeda; $\mathrm{FeSO}_{4} \cdot 9 \mathrm{H}_{2} \mathrm{O}, \mathrm{FeCl}_{2} .9 \mathrm{H}_{2} \mathrm{O}, \mathrm{Fe}\left(\mathrm{NO}_{3}\right)_{2} .9 \mathrm{H}_{2} \mathrm{O}$, dan $\mathrm{NaFeO}_{2}$. Kristal kalium ferrat memiliki warna hitam keunguan. Sampel dianalisa menggunakan spektrofotometer UV-Vis. Kami mencatat bahwa ferrate memiliki panjang gelombang 510 $\mathrm{nm}$. Kalium ferrat yang disintesis dari $\mathrm{NaFeO}_{2}$ memiliki tingkat kemurnian yang paling tinggi dibandingkan dengan sampel lainnya. Pada hasil uji degradasi, ferrat dengan pendegradasi toluene memiliki efisiensi yang tertinggi sebesar 53\% hanya dalam 10 menit waktu reaksi. Hal ini menunjukkan bahwa kalium ferrat menjadi bahan alternatif yang menjanjikan untuk pengolahan air dan limbah industri.
\end{abstract}

Kata Kunci: kalium ferrat, benzene, degradasi.

\section{Pendahuluan}

Seiring dengan perkembangan zaman, industrialisasi juga semakin berkembang. Hal ini tentu berdampak positif terhadap ekonomi masyarakat dan dapat menambah lapangan pekerjaan. Perkembangan industri juga membawa dampak negatif dan menimbulkan masalah lingkungan yang diakibatkan oleh limbah cair yang dihasilkan [1]. Tingginya beban limbah yang dihasilkan dapat menimbulkan berbagai permasalahan lingkungan [2]. Salah satu limbah hasil industri yang membahayakan lingkungan adalah polutan senyawa turunan benzena [3]-[5].

Klorobenzena, bromobenzena dan toluena merupakan golongan turunan benzena yang memiliki toksisitas tinggi dan persisten terhadap lingkungan [3]-[6]. Dengan tingkat toksisitasnya yang tinggi, klorobenzena, bromobenzena, dan toluena terdaftar dalam prioritas polutan oleh US Environmental Protection Agency [7]. Oleh karena itu degradasi limbah turunan benzena sangatlah penting dan beberapa metode telah dikembangkan guna mengatasi pencemaran limbah dan menjaga standar kualitas air. Dewasa ini, metode alternatif telah dikembangkan guna mendegradasi senyawa turunan 
benzena dengan cara elektrokimia maupun biodegradasi [8], [9]. Namun metode ini memiliki banyak kekurangan diantaranya biaya operasional yang tinggi, proses degradasi yang lama, dan memiliki efisiensi yang rendah. Sehingga dibutuhkan metode yang tepat dalam mengatasi permasalahan limbah benzena.

Dalam dekade terakhir, ferrat(VI) (Fe(VI)) mulai diteliti untuk dapat digunakan sebagai oksidator [10], [11]. $\mathrm{Fe}(\mathrm{VI})$ merupakan spesies dari besi (Fe) yang memiliki bilangan oksidasi +6 yang dikenal sebagai ion ferrat $\left(\mathrm{FeO}_{4}{ }^{2-}\right)$ [12]. Selain sebagai oksidator, $\mathrm{Fe}(\mathrm{VI})$ memiliki sifat lain diantaranya sebagai koagulan dan disinfektan [13]-[15]. Berbeda dengan oksidator lainnya, Fe(VI) merupakan oksidator yang ramah lingkungan. Dimana hasil akhir dari reaksi oksidasi oleh $\mathrm{Fe}(\mathrm{VI})$ berupa produk non-toksik, Fe(III) dan molekul oksigen [15], [16]. Kemampuan Fe(VI) sebagai disinfektan dan oksidan telah diaplikasikan dalam degradasi berbagai polutan [17]-[20]. Tujuan dari penelitian ini adalah menyintesis $\mathrm{Fe}(\mathrm{VI})$ menggunakan berbagai sumber $\mathrm{Fe}$ dan menginvestigasi aplikasi $\mathrm{Fe}(\mathrm{VI})$ dalam mendegradasi senyawa turunan benzena seperti klorobenzena, bromobenzena, dan toluena.

\section{Metode Penelitian}

\subsection{Sintesis Kalium Ferrat $\left(\mathrm{K}_{2} \mathrm{FeO}_{4}\right)$ dari Berbagai Sumber Fe}

Langkah awal pada sintesis kalium ferrat adalah pencampuran $60 \mathrm{~mL} \mathrm{NaOCl}$ dan 20 gram $\mathrm{NaOH}$. Larutan diaduk hingga $\mathrm{NaOH}$ larut sempurna. Kemudian penambahan 1 gram perhitungan logam $\mathrm{Fe}$ menggunakan $\mathrm{FeSO}_{4} .9 \mathrm{H}_{2} \mathrm{O}, \mathrm{FeCl}_{2} .9 \mathrm{H}_{2} \mathrm{O}, \mathrm{Fe}\left(\mathrm{NO}_{3}\right)_{2} .9 \mathrm{H}_{2} \mathrm{O}$, dan $\mathrm{NaFeO}_{2}$ (US paten US8961921B2 [12]). Terbentuknya sodium ferrat $\left(\mathrm{Na}_{2} \mathrm{FeO}_{4}\right)$ ditandai dengan perubahan warna larutan menjadi ungu. Pembentukan $\mathrm{K}_{2} \mathrm{FeO}_{4}$ dilakukan dengan penambahan $\mathrm{KOH}$ sebanyak 10 gram. Langkah terakhir adalah penyaringan menggunakan filter $\mathrm{GF} / \mathrm{A}$, dan pencucian menggunakan n-heksana, n-pentana, dan metanol yang bertujuan untuk menghilangkan pengotor yang berada pada kalium ferrat. Hasil akhir padatan $\left(\mathrm{K}_{2} \mathrm{FeO}_{4}\right)$ berwarna hitam keunguan. Untuk menjaga kualitas kalium ferrat dilakukan penyimpanan pada desikator.

\subsection{Uji Degradasi}

Uji degradasi ini bertujuan untuk mendegradasi senyawa turunan benzena dengan menggunakan kalium ferrat hasil sintesis terbaik. Uji degradasi dilakukan pada $\mathrm{pH}$ asam (3.4), temperatur $25^{\circ} \mathrm{C}$ dan molar rasio (kalium ferrat : senyawa target) 1:1 dengan waktu reaksi 10 menit. Degradasi senyawa turunan benzena dilakukan pada reaktor gelas tertutup dengan ukuran $700 \mathrm{~mL}$. Untuk mengontrol $\mathrm{pH}$ larutan, dilakukan dengan penambahan 5-10 mL larutan bufer. Waktu kontak reaksi dilakukan selama 10 menit dengan pengamatan kadar/konsentrasi sampel tiap menitnya.

\subsection{Karakterisasi dan Analisis Data}

Dalam penelitian ini, penentuan konsentrasi kalium ferrat menggunakan spektroskopi UV/Vis. $\mathrm{K}_{2} \mathrm{FeO}_{4}$ sebagai $\mathrm{FeO}_{4}{ }^{2-}$ memiliki absorbansi maksimum pada $510 \mathrm{~nm}$ pada larutan bufer fosfat [21]. Sehingga dalam penentuan konsentrasi kalium ferrat menggunakan absorbansi maksimum pada 510 $\mathrm{nm}$ dan koefisien absorbansi molarnya $(\varepsilon)$ adalah $1070 \mathrm{M}^{-1} \mathrm{~cm}^{-1}$ [21], [22]. Konsentrasi kalium ferrat dapat dihitung menggunakan persamaan 1, dimana $A$ adalah absorbansi, $B$ adalah lebar larutan, $C$ adalah konsentrasi. Berat molekul $\mathrm{K}_{2} \mathrm{FeO}_{4}$ adalah $198,04 \mathrm{~g} / \mathrm{mol}$.

Sampel hasil degradasi dianalisa dengan menggunakan gas chromatography (GC). Dengan kondisi temperatur injeksi dan detektor $250^{\circ} \mathrm{C}$ dan $300^{\circ} \mathrm{C}$. Temperatur awal $40^{\circ} \mathrm{C}$ (5 menit) dengan kenaikan $8^{\circ} \mathrm{C} /$ menit sampai $100^{\circ} \mathrm{C}$. Kemudian dilanjutkan kenaikan temperatur $12^{\circ} \mathrm{C} /$ menit hingga mencapai temperatur akhir $200^{\circ} \mathrm{C}$. Pada penelitian ini, dilakukan dua kali (duplo) pengulangan degradasi.

\section{Hasil dan pembahasan}

\subsection{Sintesis Kalium Ferrat $\left(\mathrm{K}_{2} \mathrm{FeO}_{4}\right)$ dari Berbagai Sumber Fe}

Pada penelitian ini, prinsip dasar sintesis ferrat menggunakan metode oksidasi basah. Zat pengoksidasi seperti $\mathrm{NaOCl}, \mathrm{O}_{3}$, dan $\mathrm{H}_{2} \mathrm{O}_{2}$ dapat mengubah tingkat oksidasi besi yang rendah $(+3) /$ $(+2)$ menjadi tingkat oksidasi yang lebih tinggi $(+6)$ [23]. Larutan campuran $(\mathrm{NaOCl}$ dan $\mathrm{NaOH})$ memiliki kemampuan oksidasi yang sangat kuat, sehingga dapat mengubah Fe pada $(+3) /(+2)$ menjadi (+6) [21]. 


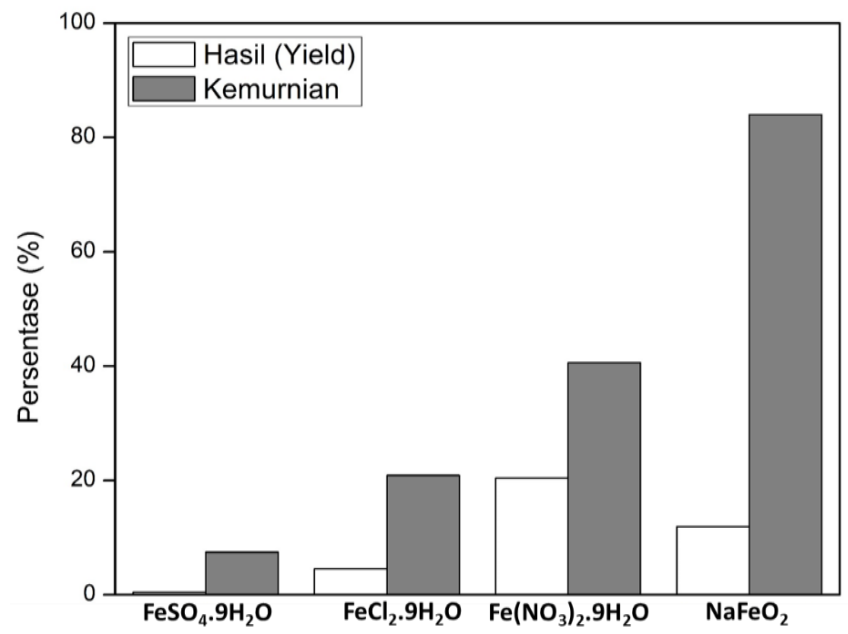

Gambar 1. Persentase hasil dan persentase kemurnian sintesis kalium ferrat

Pada penelitian ini didapatkan kemurnian ferrat hasil sintesis lebih dari $80 \%$. Kemurnian hasil sintesis dapat dihitung menggunakan persamaan dibawah (persamaan. 2) [24]. Hasil sintesis (Yield) didapatkan dari perbandingan sumber $\mathrm{Fe}$ awal dengan sumber $\mathrm{Fe}$ akhir (persamaan 3). Hasil perhitungan kemurnian dan hasil sintesis $\mathrm{K}_{2} \mathrm{FeO}_{4}$ disajikan dalam Gambar 1 .

$$
A=\varepsilon . B . C
$$

$$
\text { Persentase Kemurnian } \begin{aligned}
\mathrm{K}_{2} \mathrm{FeO}_{4} & =\frac{A}{1070} \times 0.1 \times \frac{198.04}{\text { berat sampel }} \times 100 \% \\
\text { Persentase Hasil } & =\frac{\text { gram Fe hasil }}{\text { gram Fe awal }} \times 100 \%
\end{aligned}
$$

Dari hasil penelitian menunjukkan bahwa persentase kemurnian tertinggi didapatkan menggunakan $\mathrm{Fe}$ pada $\mathrm{NaFeO}_{2}$ sebesar $85 \%$, sedangkan persentase hasil tertinggi didapatkan menggunakan $\mathrm{Fe}$ pada $\mathrm{Fe}\left(\mathrm{NO}_{3}\right)_{2} .9 \mathrm{H}_{2} \mathrm{O}$ sebesar $22 \%$. Sehingga pada penelitian ini, uji degradasi menggunakan kalium ferrat dengan tingkat kemurnian tertinggi yaitu pada sintesis kalium ferrat dengan menggunakan $\mathrm{NaFeO}_{2}$.

Pada penelitian ini (Gambar 2), hasil pengukuran serapan UV/Vis kalium ferrat pada berbagai sumber Fe dalam larutan bufer fosfat mempunyai absorbansi maksimum pada panjang gelombang 510 $\mathrm{nm}$. Absorbansi tertinggi didapatkan pada kalium ferrat menggunakan $\mathrm{NaFeO}_{2}$ sebagai sumber $\mathrm{Fe}$. Pengukuran kalium ferrat pada panjang gelombang $510 \mathrm{~nm}$. Hal ini dikarenakan tingginya kemurnian kalium ferrat mengakibatkan konsentrasi pada larutan bufer fosfat menjadi tinggi sehingga absorbansinya semakin besar [25].

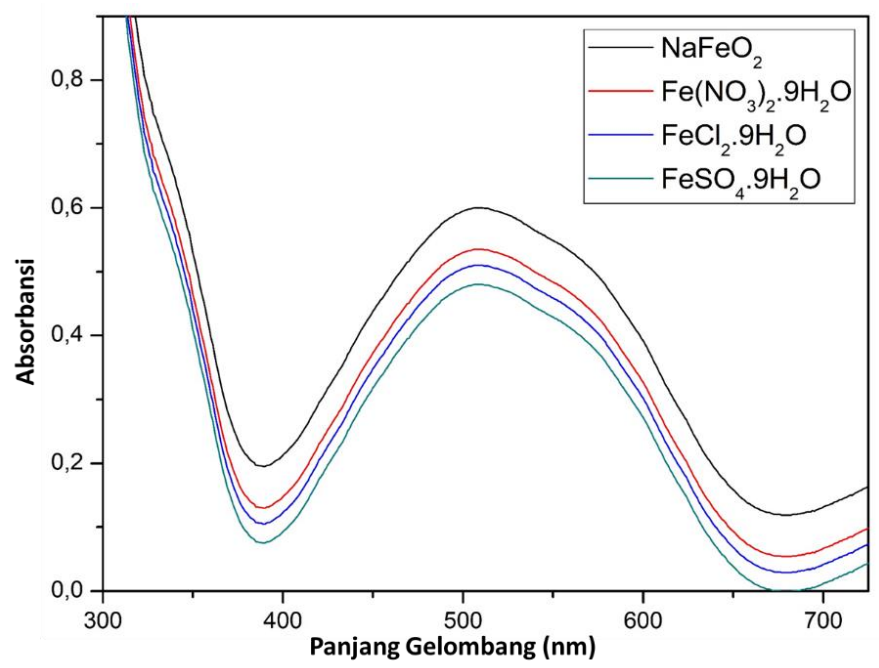

Gambar 1. Spektra kalium ferrat pada sumber Fe yang berbeda 


\subsection{Uji Degradasi}

Ferrat memiliki kemampuan oksidasi yang tinggi pada berbagai kondisi $\mathrm{pH}$ larutan [11]. Degradasi senyawa turunan benzena dengan menggunakan ferrat, larutan awal dalam reaktor berwarna keunguan dan kemudian berubah menjadi kekuningan secara cepat yang diakibatkan dekomposisi ferrat [26].

Pada hasil penelitian, kalium ferrat dapat mendegradasi senyawa turunan benzena secara cepat pada menit awal (Gambar 3) [12], [27], [28]. Pada uji degradasi senyawa turunan benzena, didapatkan efisiensi degradasi tertinggi pada degradasi senyawa toluena sebesar 53\%. Sedangkan efisiensi degradasi klorobenzena dan bromobenzena masing-masing adalah 25 dan $8 \%$.

Efisiensi degradasi yang rendah pada degradasi klorobenzena dan bromobenzena dikarenakan adanya gugus penarik elektron $(-\mathrm{Cl}$ dan $-\mathrm{Br})$, sedangkan toluena yang cenderung sebagai donor elektron $\left(-\mathrm{CH}_{3}\right)$ sehingga memiliki efisiensi degradasi yang lebih besar. Senyawa aromatik akan lebih mudah mengalami degradasi jika memiliki gugus donor elektron dibandingkan gugus penarik elektron [29].

Hasil samping pada proses degradasi ferrat berupa produk non toksik dan ramah lingkungan [16], [30]. Dalam proses degradasi polutan menggunakan ferrat, ferrat dapat terdekomposisi menjadi besi hidroksida $\left(\mathrm{Fe}(\mathrm{OH})_{3}\right)$ (Gambar 3). Selain itu, $\mathrm{Fe}(\mathrm{OH})_{3}$ merupakan endapan yang memiliki kemampuan sebagai adsorben [31]. Hal ini menjadikan ferrat sebagai nilai tambah dalam pengolahan air maupun limbah industri.

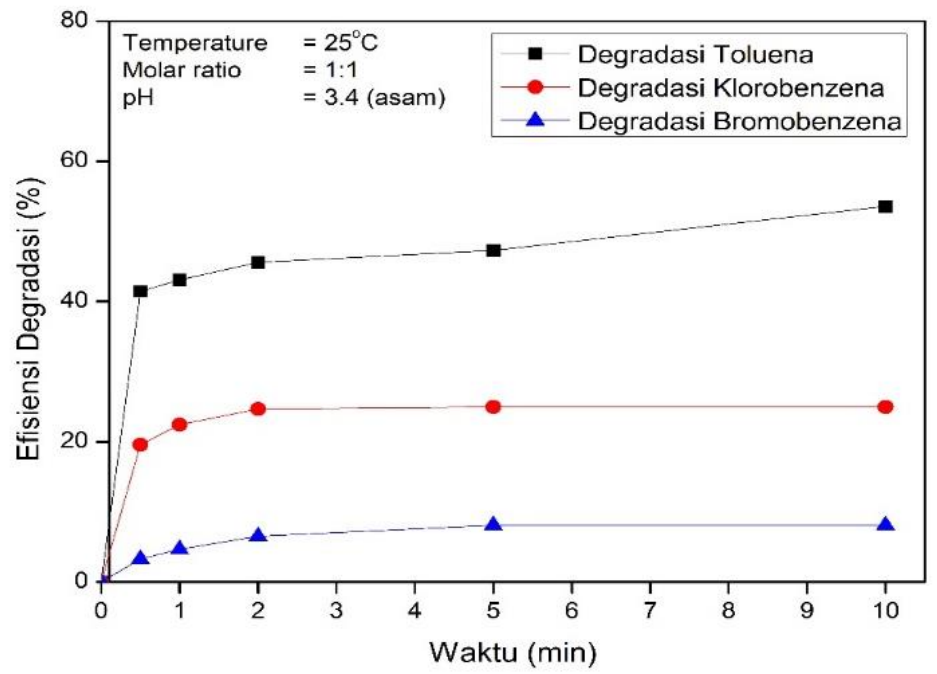

Gambar 2. Uji degradasi senyawa turunan benzena

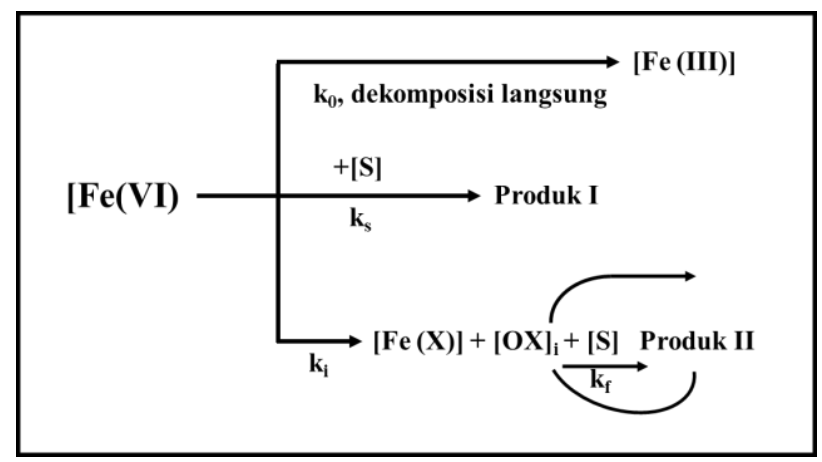

Gambar 3. Mekanisme dekomposisi ferrat menjadi Fe(III) 


\section{Kesimpulan}

Berdasarkan hasil penelitian, sintesis kalium ferrat dapat dihasilkan secara maksimal dengan menggunakan $\mathrm{NaFeO}_{2}$ sebagai sumber $\mathrm{Fe}$. Kemampuan kalium ferrat dalam mendegradasi senyawa turunan benzena meningkat dengan adanya gugus donor elektron $\left(-\mathrm{CH}_{3}\right)$ seperti toluena.

\section{DAFTAR PUSTAKA}

[1] R. Nurhayati and N. Kusumawati, "Pemanfaatan kalium ferrat dalam pengolahan limbah pewarna," Inotek, vol. 16, 2012.

[2] S. Wulandari and S. Anshar, "Degradasi Limbah Cair Kelapa Sawit dengan Penambahan Bakteri Rizosfir Actinomycetes dan Tanaman Typha Angustifolia dengan Model Constructed Treatment Wetland (CTW)," J. Biog., vol. 11, pp. 55-60, 2014.

[3] S. D. Pravasi, "Chlorobenzene A2 - Wexler, Philip BT - Encyclopedia of Toxicology (Third Edition)," Oxford: Academic Press, 2014, pp. 870-873.

[4] M. A. Bryant, "Bromobenzene A2 - Wexler, Philip BT - Encyclopedia of Toxicology (Third Edition)," Oxford: Academic Press, 2014, pp. 559-560.

[5] S. R. Clough, "Toluene A2 - Wexler, Philip BT - Encyclopedia of Toxicology (Third Edition)," Oxford: Academic Press, 2014, pp. 595-598.

[6] E. Selli, C. L. Bianchi, C. Pirola, G. Cappelletti, and V. Ragaini, "Efficiency of 1,4dichlorobenzene degradation in water under photolysis, photocatalysis on $\mathrm{TiO} 2$ and sonolysis," J. Hazard. Mater., vol. 153, no. 3, pp. 1136-1141, 2008.

[7] USEPA, "National pollutant discharge elimination system," Code Fed. Regul., no. 1988, 1988.

[8] N. Musilová-Kebrlová, P. Janderka, and L. Trnková, "Electrochemical processes of adsorbed chlorobenzene and fluorobenzene on a platinum polycrystalline electrode," Collect. Czechoslov. Chem. Commun., vol. 74, pp. 611-625, 2009.

[9] M. V Monferrán, J. R. Echenique, and D. A. Wunderlin, "Degradation of chlorobenzenes by a strain of Acidovorax avenae isolated from a polluted aquifer," Chemosphere, vol. 61, no. 1, pp. 98-106, 2005.

[10] S. J. de Luca, C. N. Idle, and A. C. Chao, "Quality improvement of biosolids by ferrate(VI) oxidation of offensive odour compounds," Water Sci. Technol., vol. 33, no. 3, pp. 119-130, 1996.

[11] G. W. Thompson, L. T. Ockerman, and J. M. Schreyer, "Preparation and Purification of Potassium Ferrate. VI," J. Am. Chem. Soc., vol. 73, no. 3, pp. 1379-1381, Mar. 1951.

[12] V. K. Sharma, "Apparatus and Method For Producing Liquid Ferrate," 31-Mar-2011.

[13] J. Jiang, "Advances in the development and application of ferrate ( VI ) for water and wastewater treatment," no. September, pp. 165-177, 2014.

[14] C. Li, X. Z. Li, N. Graham, and N. Y. Gao, "The aqueous degradation of bisphenol A and steroid estrogens by ferrate," Water Res., vol. 42, no. 1, pp. 109-120, 2008.

[15] V. K. Sharma, "Potassium ferrate(VI): an environmentally friendly oxidant," Adv. Environ. Res., vol. 6, no. 2, pp. 143-156, 2002.

[16] J.-Q. Jiang and B. Lloyd, "Progress in the development and use of ferrate(VI) salt as an oxidant and coagulant for water and wastewater treatment," Water Res., vol. 36, no. 6, pp. 1397-1408, 2002.

[17] A. Al-Abduly and V. K. Sharma, "Oxidation of benzothiophene, dibenzothiophene, and methyl-dibenzothiophene by ferrate(VI)," J. Hazard. Mater., vol. 279, pp. 296-301, Aug. 2014.

[18] R. C. Pepino Minetti, H. R. Macaño, J. Britch, and M. C. Allende, "In situ chemical oxidation of BTEX and MTBE by ferrate: pH dependence and stability," J. Hazard. Mater., vol. 324, pp. 448-456, 2017.

[19] G. A. K. Anquandah and V. K. Sharma, "Oxidation of octylphenol by ferrate(VI)," J. Environ. Sci. Heal. Part A, vol. 44, no. 1, pp. 62-66, Jan. 2009.

[20] Y. Jiang, J. E. Goodwill, J. E. Tobiason, and D. A. Reckhow, "Impacts of ferrate oxidation on natural organic matter and disinfection byproduct precursors," Water Res., vol. 96, pp. 114125, 2016.

[21] V. Sharma, C. R. Burnett, and F. Millero, Dissociation constants of the monoprotic ferrate(VI) ion in NaCl media, vol. 3. 2001.

[22] S. Licht et al., "Analysis of ferrate(VI) compounds and super-iron Fe(VI) battery cathodes: 
FTIR, ICP, titrimetric, XRD, UV/VIS, and electrochemical characterization," J. Power Sources, vol. 101, no. 2, pp. 167-176, 2001.

[23] J. Chengchun, L. Chen, and W. Shichao, "Preparation of Potassium Ferrate by Wet Oxidation Method Using Waste Alkali: Purification and Reuse of Waste Alkali," in Ferrates, vol. 985, American Chemical Society, 2008, pp. 5-94.

[24] Y.-L. Wei, Y.-S. Wang, and C.-H. Liu, "Preparation of Potassium Ferrate from Spent Steel Pickling Liquid," Metals (Basel)., vol. 5, no. 4, pp. 1770-1787, 2015.

[25] Y. Lee, M. Cho, J. Y. Kim, and J. Yoon, Chemistry of ferrate (fe(vi)) in aqueous solution and its applications as a green chemical, vol. 10. 2004.

[26] M. Dian and K. Il-Kyu, "Degradation of Toluene by Liquid Ferrate(VI) and Solid Ferrate(VI) in Aqueous Phase," J. Environ. Eng., vol. 144, no. 9, p. 4018093 , Sep. 2018.

[27] F. B. Laksono and I. Kim, "Removal of 2-Bromophenol by Advanced Oxidation Process with In- situ Liquid Ferrate ( VI )," pp. 128-135, 2016.

[28] J.-H. Nam, I.-K. Kim, J. Kwon, and Y. Do Kim, "Applications of electrochemical ferrate(VI) for degradation of trichloroethylene in the aqueous phase," Desalin. Water Treat., vol. 57, no. 11, pp. 5138-5145, Mar. 2016.

[29] C. Bougheloum and A. Messalhi, "Photocatalytic Degradation of Benzene Derivatives on TiO2 Catalyst," Phys. Procedia, vol. 2, no. 3, pp. 1055-1058, 2009.

[30] N. Graham, C. Jiang, X.-Z. Li, J.-Q. Jiang, and J. Ma, "The influence of pH on the degradation of phenol and chlorophenols by potassium ferrate," Chemosphere, vol. 56, no. 10, pp. 949-956, 2004.

[31] B. Gu, J. Schmitt, Z. Chen, L. Liang, and J. F. McCarthy, "Adsorption and desorption of natural organic matter on iron oxide: mechanisms and models," Environ. Sci. Technol., vol. 28, no. 1, pp. 38-46, Jan. 1994. 